\title{
Assessment of Self- Medication Practice and Contribution Factor in Arada Sub City Addis Ababa, Ethiopia
}

\author{
TAKELE ACHALU \\ Arada sub-city FMHACA, Addis Ababa, Ethiopia \\ Daniel Emana \\ School of Medical Laboratory, Jimma University, Ethiopia
}

\begin{abstract}
Background: - a number of individuals in developing countries do not attend physicians for their illnesses; instead they commonly use self-medication. Self-medication could be using drugs existing in home like over the counter (OCT) drugs, traditional medicine or non- pharmacological action. Aim of this study was to assess the practice of self-medication in Arada Sub city town, Addis Ababa, EthiopiaMethods: - a community based cross sectional study was carried out in Arada sub City from Feb 20 to Feb 27, 2019. Data was collected by Semi-structured and pre-tested questionnaire, consisting questions on general demographic, socio-economic as well as on perceived illness /symptoms in two weeks recall period and actions taken for it; and administered to respondents of the 412 systematically selected households. The data was analyzed and presented using tables and chi-square calculation.Result: - Out of the 386 individuals with perceived illness, 142 (39.9\%) were self-medicated and females $82(58.27 \%)$ were more self-medicated than males. The most frequent illness/symptom reported for selfmedication was fever (40.6\%). Most of the drugs (41.95\%) used for self-medication were obtained from drug retail outlets, and previous experience for the perceived low severity of illness/symptoms (41.1\%) was the main reason for self-medication.Conclusion \& Recommendation:- Self-medication is widely practiced for a wide range of illnesses/symptoms and by using OTC drugs, prescription only drugs and also traditional medicine/nonpharmacological action. The public as well as the health care providers have to be educated on the scope of selfmedication; i.e., the type of illnesses to be self-diagnosed and self-treated, and the type of drug products to be used in order to promote responsible self-medication.
\end{abstract}

Keywords: Self-medication; Arada subcity, OTC drug

DOI: $10.7176 / \mathrm{JHMN} / 74-02$

Publication date:May $31^{\text {st }} 2020$

\section{INTRODUCTION}

Background: Out of the known many symptoms several peoples are experiences, only a small proportion with an estimate of $10-30 \%$, are brought to the attention of physicians. This presumes that the majority of the symptoms is either tolerated or self-medicated (1). Self-care is a response of individuals to promote or restored their health. Self-medication one form of self-care is the selection and use of medicines by individuals to treat self- recognized illnesses or symptoms of illnesses (2). Self- medication involves the use of medicinal products by the consumer to treat self- recognized disorders or symptoms, or the intermittent or continued use of medication prescribed by a physician for chronic or recurring diseases or symptoms (3).

Self-medication as defined by World Self-medication Industry (WSMI) is the treatment of common health problems with medicines specially designed and labeled for use without medical supervision and approved as safe and effective for such use (4). The extra ordinary increases in the cost of traditional health care in recent decades -doctors, hospitals, prescriptions etc causes some individuals to desperately try to find more affordable alternatives to treat or prevent their own afflictions(4). For minor illness people have often restored to self-medication, preferring an over the counter(OTC) service at their pharmacists to the time consuming visit to a doctor(5).

The type and extent of self-medication, and the reasons for it may vary from country to country. In developing countries, both modern drugs and traditional medicines are commonly used for self-medication (1). Although some health care providers attach negative connotations to it, the world health organization (WHO) acknowledges the existence of availed role of self-medication (2). Responsible self-medication can be used to prevent and treat symptoms and ailments that do not need medical consultation or over sight. This reduces pressure on medical services, especially when these are limited (3).

People in lower socio-economic groups are less likely to visit a physician when experiencing physical symptoms of illnesses probably related to their ability to pay (6). Most people affected by malaria do not attend general health care facilities. Even if a consultation is made, patients are likely to attend these health facilities only if home treatment is not successful (7). The demand for health care continues to grow faster than the gross national products in many counties. This demand will increase over the fore seeable future. One possible way to alleviate the rise in the demand is to increase self-medication products for treatment of minor ailments, with consumers responsible self-medicating rather than visiting physicians (2). The aim of this study was to determine the practice 
of self-medication in Arada Sub city town, Addis Ababa, Ethiopia

\section{Methods \\ Study area and Design}

The study was conducted in Arada sub city, Addis Ababa the capital city of Ethiopia. According to Central Statistical Agency (CSA) 2017 population projection the total population of Arada Sub-City were 265,141 out of them 141,696 were female.

The sub city is located in the center of Addis Ababa and various population of people living in the Arada sub city, which belonging to different ethnic groups of the country. The sub city have six General hospital and nine health center and above 60 private clinics and drug retail outlets. The study was conducted from February 20, to February 27, 2019. A community based cross-sectional study design was carried out using semi- structured questionnaire, consisting of the general socio- demographic, socio- economic, perceived illnesses and actions taken to overcome the illness, among patients with two weeks of illness prior to the interview.

\section{Sample Size and Sampling Techniques}

According to the population projection of Central Stastical Agency (2007) 15,000 households were found, from these 5055 houses were selected. Using systematic random sampling technique the minimum sample size was determined from the total households of the town by the following formula:

$n=\left(N z^{2} p(1-p)\right) /\left(d^{2}(N-1)\right)$

Where: $\mathrm{n}=$ sample size

$\mathrm{N}=$ total number of household

$Z=$ The standard normal value Confidence interval $Z=1.96$ at $95 \%$ confidence interval

$\mathrm{P}=$ Estimate of the prevalence of self-medication, which is the Default prevalence of self-medication

$\mathrm{D}=$ Margin of error $=0.05 ; \mathrm{n}=$ is the minimum sample size possible and $10 \%$ Non-responded was added, so sample size is $384+10 \%(384)=423$

Therefore, sample size of 423 was considered. The samples selected out of the 5055 households of the town by systematic random sampling technique and lottery methods, i.e. every 5055/423th household was selected and the head of the household or other member of the household aged above 18 is interviewed.

From the 423 semi-structured questionnaire, 412 were filled correctly while 4 questionnaire not. The rest 07 questionnaires are used for pretest and training data collectors.

\section{Data Collection Instrument}

A well- structured questionnaire was used to collect the necessary in formation the variables to be collected include socio- demographic socio-economic and questions on self- medication. The questionnaire was prepared in English language to achieve consent from both administrators of the town and interviewee a detailed explanation on the aim of the study was communicated before data collection.

\section{Data Collection}

A semi- structured questionnaire is used to collect the necessary information. The variables to be collected include socio- demographic and socio- economic characteristics as well as type of action taken (self-medication practice) and related data of the study area and individuals with perceived illness in 6 weeks of recall period.

The data is collected by university students who are in vacation during the study period. The validity and reliability of the data collection format is pre-tested before the actual study period. The test is performed on households not included in the actual study.

\section{Ethical Considerations}

An official letter was written from Arada sub-city FMHACA and Arada sub-city health sector to Responsible body to get permission for data collection, verbal consent from the respondents was obtained and they were convinced on confidentiality of the information that they gave.

\section{Limitation of the study}

- Shortage of time and money

- Unwillingness to respond from some respondent.

- Because of the smallness of the sample size, the result of the study may not be the exact reflection of the real situation.

\section{Results}

From the 423 sampled households, heads of 412 households/members of the household aged above 18 were 
interviewed using semi-structured questionnaire during the study period. Majority of the respondents $325(78.88 \%)$ were females and about three fourth of them 306(74.27\%) were aged under 45 while only $4(0.97 \%)$ were aged above 64 . Three hundred forty three $(83.25 \%)$ of household heads were married. Around half $221(53.64 \%)$ of head of households were illiterate while the least 23(5.58\%) had attended secondary education (9- 12). Occupational status of around half $208(50.49 \%)$ of head of households were business man and only $8(1.94 \%)$ were retired from governmental organization is their only source of income. $192(46.60 \%)$ of heads of households had monthly income of between 150 and 300 birr while only 39(9.47\%) had monthly income of above 600 birr. (See table 1 below). In the absence of parents children above 18 age or the elder of the house were interviewed.

Table 1: Socio-demographic characteristics reports of households' head. Arada sub city, Addis Ababa, Ethiopia, Feb. 2019.

\begin{tabular}{|c|c|c|c|}
\hline \multicolumn{2}{|c|}{ Socio-demographic characteristics } & \multirow{2}{*}{$\begin{array}{c}\text { Frequency } \\
87\end{array}$} & \multirow{2}{*}{$\begin{array}{c}\text { Percentage } \\
21.12\end{array}$} \\
\hline Sex & Male & & \\
\hline & Female & 325 & 78.88 \\
\hline & Total & 412 & 100 \\
\hline \multirow{7}{*}{ Age } & $18-24$ & 123 & 29.85 \\
\hline & $25-34$ & 107 & 25.97 \\
\hline & $35-44$ & 76 & 18.45 \\
\hline & $45-54$ & 91 & 22.09 \\
\hline & $55-64$ & 11 & 2.67 \\
\hline & $>65$ & 4 & 0.97 \\
\hline & Total & 412 & 100 \\
\hline \multirow{5}{*}{ Marital status } & Un married & 18 & 4.37 \\
\hline & Married & 343 & 83.25 \\
\hline & Widow & 38 & 9.22 \\
\hline & Divorce & 13 & 3.16 \\
\hline & Total & 412 & 100 \\
\hline \multirow{7}{*}{ Educational status } & Illiterate & 221 & 53.64 \\
\hline & Write and read & 36 & 8.74 \\
\hline & Elementary (1-4) & 41 & 9.95 \\
\hline & Junior (5-8) & 64 & 15.53 \\
\hline & Secondary (9-12) & 23 & 5.58 \\
\hline & Higher institution $10+/ 12+$ & 27 & 6.55 \\
\hline & Total & 412 & 100 \\
\hline \multirow{8}{*}{ Occupation } & Merchant & 208 & 50.49 \\
\hline & Daily laborer & 82 & 19.90 \\
\hline & Private employee & 51 & 12.38 \\
\hline & Government employee & 33 & 9.01 \\
\hline & Farmer & 17 & 4.13 \\
\hline & Retire & 8 & 1.94 \\
\hline & Other & 13 & 3.16 \\
\hline & Total & 412 & 100 \\
\hline \multirow{5}{*}{ Income } & $<150$ & 78 & 18.93 \\
\hline & $150-300$ & 192 & 46.60 \\
\hline & $301-600$ & 103 & 25.00 \\
\hline & $>600$ & 39 & 9.47 \\
\hline & Total & 412 & 100 \\
\hline
\end{tabular}

In this study the frequency of reported illnesses revealed that eading cases are fever(40.6\%), headache 33 $(23.1 \%)$, cough and cold $16(11.2 \%)$.(Table 2$)$ 
Table 2: Frequency of the reported symptoms/illness Arada sub city, Addis Ababa, Ethiopia, Feb 2019

\begin{tabular}{|l|l|l|}
\hline Illness & Frequency & \multicolumn{1}{c|}{$\%$} \\
\hline Cough \& cold & 16 & 11.2 \\
\hline Fever & 58 & 40.6 \\
\hline Headache & 33 & 23.1 \\
\hline Gastric pain & 6 & 4.2 \\
\hline Abdominal pain & 2 & 2.1 \\
\hline Diarrhea & 5 & 3.5 \\
\hline Eye disease & 4 & 4.2 \\
\hline Other & 18 & 13.3 \\
\hline Total & 142 & \\
\hline
\end{tabular}

Also the study showed that from the total of 142 respondents $56(39.5 \%)$ were self- medicated, $67(47.2 \%)$ in health institution, $7(2.8 \%)$ non pharmacologically $12(8.5 \%)$ no action taken. (Table 3 )

Table 3: Measurement taken by respondents. Arada sub city, Addis Ababa, Ethiopia, Feb. 2019.

\begin{tabular}{|l|l|l|}
\hline Variable & Frequency & $\%$ \\
\hline Self-medication & 56 & 39.5 \\
\hline Health institution & 67 & 47.2 \\
\hline Non Pharmacologically & 7 & 2.8 \\
\hline No action taken & 12 & 8.5 \\
\hline Total & 142 & 100 \\
\hline
\end{tabular}

The drug used for self-medication were obtained from drug out let 13(41.95\%), 3(9.7\%) from market, $5(16.1 \%)$ of consumed drugs were left over from past prescription, 1(3.2\%) was obtained from neighbor (Table 4).

Table 4: Source of modern drug Arada sub city, Addis Ababa, Ethiopia, Feb. 2019

\begin{tabular}{|l|l|l|}
\hline Source of drug & Number & $\%$ \\
\hline Drug vendors & 03 & 9.7 \\
\hline Drug store & 10 & 32.25 \\
\hline Market & 03 & 9.7 \\
\hline Neighbor drug & 01 & 3.2 \\
\hline Left over drug in the house & 05 & 16.1 \\
\hline Total & 22 & \\
\hline
\end{tabular}

From 56 individuals interviewed who were self-medicated $37(66.9 \%)$ were females and $19(33.9 \%)$ were males. Majority 22(39.3\%) were illiterate and $17(30.4 \%)$ can only read and write, whereas $10 \quad(17.9 \%)$ primary school complete, $5(9 \%)$ secondary and $2(3.5 \%)$ were in the level of higher institution. Action taken for illness and level of education showed no significant $(\mathrm{P}>0.05)$ statistical association.

Merchants/petty traders 29 (51.8\%) experienced more self-medication while few employed individuals 8 (14.3\%) practiced self-medication. Almost two-third of the family of persons who practiced self-medication had a monthly income of less than 150 Birr. Monthly income showed no statistically significant association $(\mathrm{P}>0.05)$ with action taken for illness. (Table 5) 
Table 5: Difference in proportion of respondents who reported illness/symptom by sex, education, occupation \& income. Arada sub city, Addis Ababa, Ethiopia, Feb. 2019.

\begin{tabular}{|c|c|c|c|}
\hline \multirow[b]{2}{*}{ Variables } & Action taken & \multirow[b]{2}{*}{ P-value } & \\
\hline & Self-medication $\quad$ No $(\%)$ & & \\
\hline \multirow[b]{2}{*}{ Sex } & Male & $19(33.9)$ & \\
\hline & Female & $37(66.12)$ & \\
\hline \multirow{5}{*}{ Education } & Illiterate & $22(39.3)$ & \multirow[t]{5}{*}{$\mathrm{P}>0.05$} \\
\hline & Read \& write only & $17(30.3)$ & \\
\hline & Primary school & $10(17.8)$ & \\
\hline & Secondary school & $5(8.9)$ & \\
\hline & Higher institution & $2(3.6)$ & \\
\hline \multirow{4}{*}{ Occupation } & Employ & $8(14.93)$ & \multirow[t]{4}{*}{$\mathrm{P}<0.05$} \\
\hline & Farmer & $10(17.8)$ & \\
\hline & Merchant & $29(51.8)$ & \\
\hline & Other & $9(16.0)$ & \\
\hline \multirow{4}{*}{ Income } & $<150$ & $78(18.93)$ & \multirow{4}{*}{$\mathrm{P}>0.05$} \\
\hline & $150-300$ & $192(46.60)$ & \\
\hline & $301-600$ & $103(25.00)$ & \\
\hline & $>600$ & $39(9.47)$ & \\
\hline
\end{tabular}

The study revealed that reported symptom/illness of the respondents were complained as follows $6(9.2 \%)$ gastric pain, $16(63.8 \%)$ cough and cold, 58(40.8) fever, 33(23.24) headache, 2(1.4\%) abdominal pain, 5(3.5\%) diarrhea, $4(3 \%)$ eye disease, $18(12.7 \%)$ others symptoms/illness. Among the respondents who took self-medication the majority had taken for headache followed by fever and the least were for gastric pain and eye disease (Table $6)$.

Table 6: Reported symptom/illness \& action taken, Arada sub-city, Addis Ababa, Ethiopia, Feb. 2019.

\begin{tabular}{|l|l|l|l|l|l|}
\hline \multirow{2}{*}{ illness } & \multicolumn{5}{|c|}{ Action taken byck people } \\
\cline { 2 - 6 } & $\begin{array}{l}\text { Self- } \\
\text { medication }\end{array}$ & $\begin{array}{l}\text { Health } \\
\text { institution }\end{array}$ & Non pharmacological & $\begin{array}{l}\text { No action } \\
\text { taken }\end{array}$ & Total \\
\cline { 2 - 6 } & No(\%) & No(\%) & No(\%) & No(\%) & \\
\hline Gastric pain & $1(1.8)$ & $5(7.4)$ & 0 & 0 & 6 \\
\hline Cough \& cold & $6(10.7)$ & $7(10.3)$ & $3(42.8)$ & 0 & 16 \\
\hline Fever & $20(35.7)$ & $33(48.5)$ & $2(28.6)$ & $3(25)$ & 58 \\
\hline Headache & $23(41.1)$ & $8(11.7)$ & 0 & $2(16.7)$ & 33 \\
\hline Abdominal pain & $2(3.6)$ & 0 & 0 & 0 & 2 \\
\hline Diarrhea & 0 & $3(4.4)$ & $2(28.6)$ & 0 & 5 \\
\hline Eye disease & $1(1.8)$ & 0 & 0 & $3(25)$ & 4 \\
\hline Other & $2(4.2)$ & $12(16.3)$ & 0 & $4(33.4)$ & 18 \\
\hline Total & $55(100)$ & $68(100)$ & $7(100)$ & $12(100)$ & 142 \\
\hline
\end{tabular}

\section{DISCUSSION}

In this study the prevalence of self-medication was reported to be $39.5 \%$, which is almost similar with the studies done in Mexico (30\%), India (34.5\%) and China (32.5\%). Studies conducted in Jimma and in three towns of North West Ethiopia revealed the prevalence of self-medication was $27.6 \%$ and $27.2 \%$ respectively $(1,9,10)$. In another studies conducted in Sudan and Jordan indicated the prevalence was $81.8 \%$ and $42.5 \%$ respectively $(10,12)$. The difference from the figures in this study could probably because of the difference in the methodology (recall period).

The study also reported that females practice more self- medication $(66.12 \%)$ than males $(33.9 \%)$ did, and this finding is in agreement with the studies done in Jimma (Ethiopia), Sudan and Mexico that identified females as the fundamental element in the consumption of drugs and implementation of self-medication $(9,12)$. From children with perceived illness aged $<5$ year in this study were self-medicated where as in Kenya, Nigeria and Mali $47 \%, 70.5 \%$, and $75.8 \%$ respectively were managed at home with ant malarial drugs (7). The variation from the result in this study could probably is because of the difference in the recall period as one factor. It was reported that older people above 64 were less likely $(0.97 \%)$ to practice self-mediation than middle aged (25-64) ones $(47.09 \%)$. This result is similar with the finding in Sudan and Jordan where older people practiced Self-medication less commonly unlike most middle aged ones $(10,12)$.

Unlike a study conducted in Sudan, where Self-medication was least common with the low level of education (illiterate and primary supply /intermediate school) (12), in this study individuals with low level of education (illiterate, informal education and below grade 5) (72.33\%) were the most commonly self-medicated individuals. Less than half (47.2\%) of studied subjects in this study have visited H/F, this could be because of the fact that the 
subjects of this study are urban dwellers, which are supposed to have a better knowledge and access interims of distance to modern health care services as compared to their rural counter parts (1).

The commonest illness/symptoms that lead to self-medciation in this study were headache/fever, cough and GI/abdominal problem, which were also reported similarly in Jimma (Ethiopia), France and Brazil (9). A study conducted in Addis Ababa indicated Headache/fever, URTIs and GI illnesses or symptoms of illnesses of short duration are usually self-limiting and amenable to simple homemade remedy and some OTC drugs (2).

The percentage of individuals who didn't take any action against their illness/symptom were $12(8.5 \%)$ which is similar with a study conducted in three towns of north west Ethiopia where relatively low individuals $332(27.9 \%)$ took no action (1). The variation in the figures is probably because of differences in study area coverage and methodology (recall period). Unlike the studies done in Jimma and three towns of North West Ethiopia where people used S/M mainly because of its relative less cost $(1,9)$ and in Jordan because of the ailments were believed too minor to see a doctor (46.4\%) (10), This finding is in agreement with a study done in china where people used S/M mainly because they felt that they know what to do (9) and also $18.2 \%$ of participants of a study conducted in Addis Ababa was did so (2). In another study done in rural communities of Butajira, southern Ethiopia $59.9 \%$ (28) individuals bought antimalarial drugs without prescription because of prior knowledge of the same drug for the same illness/symptom (7).

From the medications used for self- medications in this study $26(46.43 \%)$ were TM, which is similar with a study done in Sudan (40.7\%). The majority of African populations use TM for their health careen need, and in Japan S/M is firmly based on TM (herbal products) $(15,16)$. The role of both TM and MM on S/M has been described in studies conducted in Ethiopia, a study on inpatients of the then Jimma hospital indicated that $26.5 \%$ of those from rural areas and $12.4 \%$ from urban areas had used TM (17). Self- medication mainly using MM in another part of the world is a widely employed practice as compared to what has been reported in Ethiopia $(1,12)$. Another study conducted in Addis Ababa indicted that almost all (95\%) of studied subjects reported that they have used at one time or another herbal remedies for self- care, and $20 \%$ of the participants in the same study preferred Traditional Medicine while 75\% both Traditional Medicine and MM, and only 5\% preferred MM for self-care (2). The preference to Traditional Medicine is probably because of the believe that natural products are safer than the synthetic ones, and lack of awareness towards the serious risks of using both Traditional Medicine and MM together in the society (1).

From the $78(18.93 \%$ from the total $)$ households having monthly income of less than 150 birr the majority have used self-medication at least one time in the two weeks recall period, 23(41.1\%) low severity of illness and $6(10.7 \%)$ with perceived illness used self- medication because of its low cost alternativeness. This result is similar with a study done in Sudan where lowest income earners practiced more self- medication (12). As WHO noted, self- medication provides a cheap alternative to people who cannot afford to pay medical practitioners. Thus selfmedication is often the first response to illnesses among people with low income (9). The study also uncovered that the availability of drugs that use to save time 7 (12.5\%), distance from H/F, expectation of less benefte from $\mathrm{M} / \mathrm{M} 13(23.2 \%)$ contribute largely for the increased practice of self- medication. (9). In a similar study in Jordan, the main sources of antibiotics for S/M were left over from previous use and from DROs (11). The encouraging factors for the purchase of antimalarial drugs from unofficial sectors include, lack of access to formal health services, inadequate services (shortage of drugs and long waiting time) and the easy availability of OTC treatment (7).

From the modern drug used for Self- medication in this study $57.14 \%$ were obtained from DROs, which is almost similar with the findings of the study done in Jimma town (52.4\%) (9). Another study in rural communities of Butajira indicated that $55 \%$ of the study population had ever bought ant malarial drugs from DROs, market or any shop. Similarly in Guatemala $55 \%$ of participants of the study bought ant malarial drugs from local stores and pharmacies, and in Kenya from pharmacies (54\%) and market (9.7\%) (7).

Drug consumers who want to save drugs for future use and share drugs pose special attention particularly in case of antimicrobials. Therefore, people storing antimicrobials have to be made aware of the fact that these drugs should be taken in full dose and may expire in due course; in addition the illness/symptoms they might face could be different from the previous ones though symptoms may appear similar (6). Now a day, despite the exciting development and improvement in drugs and pharmaceutical industry, the biological equilibrium between the antibacterial factors developed by man and the pathogenic microorganisms is progressively shifting in favor of the pathogens (17).

It is only by the more careful use of antimicrobials that emergency and spread of resistance will be controlled. This will require the collaboration of groups which include prescribes, dispensers, patients, government and industry including the agriculture, aquaculture and horticulture industries (18).

\section{CONCLUSION AND RECOMMENDATION}

A significant number of people (36.79\%) use Self-medication in Arada sub city. The self- medication behavior of the town varies significantly with a number of socio-demographic characteristics and it is more prevalent among 
females, middle aged and lowest income earning individuals/households. There is also a statistically significant association between; the type of illness/symptom, educational level, marital status, occupation and monthly income of the population and solutions sought. But no association is found between the action taken for illness/symptom and, sex and religion of the population.

The major reason for Self-medication is reported to be previous experience for the illness/symptom and measures taken. Drug retail out let, are cited to be the major sources of drugs that are used for Traditional Medicine. The increased hoarding of drugs to treat similar illness/symptom and drugs left over from previous use contribute to the increase in the $\mathrm{S} / \mathrm{M}$ practice.

Much has to be done in educating the public including the health care providers on the type of illnesses that can be self-diagnosed and self-treated, the type of drugs to be used for, Traditional Medicine the proper use of antimicrobials and the dangers of sharing and using left over drugs.

During dispensing of drugs due emphasis should be given to all drug consumers particularly the illiterate, children, elderly, pregnant, breast feeding mothers and those with chronic illnesses.

Drug Administration and Control Authority (DACA) needs to effectively implement laws on drug handling and dispensing so as to take necessary measures on illegal providers of drugs. The Federal Ministry of Health $(\mathrm{MOH})$ and the regional health bureau may need to facilitate ways so as to increase health service delivery institutions and quality of service delivered as well, so that more people can have access for utilizing health facilities.

Finally, further study needs to be done in the study area to understand especially self- treatment practice of malaria in the study area.

\section{Competing interests}

We declare that there is no competing interest among researchers.

\section{Authors' contributions}

TA: participated from the very beginning study design, data collection and analysis of the data. DE: Designing of the study, interpretation of the finding, reviewing the manuscript and draft write up.

\section{Acknowledgement}

We would like to acknowledge the colleagues and the head of Arada sub city administration and drug and food administration staff of Addis Ababa for giving us useful data and sharing valuable information while developing the proposal and data collection periods. Lastly but not least, we would also like to thank all data collectors and others who support in professional advises during data analysis.

\section{REFERENCES}

1. Teferra A. and Alemayehu W. Self-medication in three towns of northwest Ethiopia. Ethiopian journal of health development. 2001; 15(1):25-30.

2. Tenaw A. and Tsige G. Self-medication practice in Addis Ababa: A prospective study. Ethiopian journal of health science. $2004 ; 14(1): 1-11$.

3. WHO drug information? 2000; 14(1):1-26.

4. What is self-medication" wami.org. WORLD SELF-MEDICATION INDUXTRY retrieved May 25, 2016

5. Khantzian E.J. (1997). "The self-medication hypothesis of drug use disorders: A reconsideration and recent applications". Harvard Review of Psychiatry. 4 (5): 231-244. doi:10.3109/10673229709030550. PMID 9385000.

6. Adam Smith Institute Blog - self - medication. http://www.adamsmith.org.com

7. Tenaw A. and Tsige G. Assessment of consumers drug knowledge in Addis Ababa: Across-sectional survey. Ethiopian journal of health science 2004; 14(2):71-80.

8. Wakgari Deressa, A. Ali and F. Enqusellassie. Self-treatment of malaria in rural communities, Butajira, Southern Ethiopia. Bulletin of WHO 2003;81(4).

9. Solomon W. and Abebe G. Practice of self-medication in Jimma town. Ethiopian journal of health development. 2003; 17(2):111-116.

10. Self-medication pattern in Amman, Jordan. http://www.ncbi.nih.gov.com

11. Self-medication practice in Khartoum state, Sudan. http://www.ncbi.nlm.nih.gov.com

12. WHO drug information $2004 ; 18(1): 27$.

13. WHO drug information 1988; 2(2):65.

14. Yilikal Alemu, F Lemma and A. G/Mariam. Utilization of traditional medicine among inpatients of Jimma hospital, south west Ethiopia. Jimma University. 1994:4(1):30-31.

15. WHO drug information 1999; 13(4):230. 